\title{
Role of glycoprotein 78 and cidec in hepatic steatosis
}

\author{
JIE LI $^{1 *}$, GUOCAI LIU ${ }^{2 *}$, FENG ZHANG ${ }^{1}$, ZHIWEN ZHANG $^{1}$, YUQIAO XU ${ }^{1}$ and QING LI $^{1}$ \\ ${ }^{1}$ State Key Laboratory of Cancer Biology, Department of Pathology, Xijing Hospital, Basic Medical \\ College, Fourth Military Medical University, Xi'an, Shaanxi 710032; ${ }^{2}$ The Third Department of \\ Internal Medicine, The 273 Hospital of Chinese PLA, Korla, Xinjiang 84100, P.R. China
}

Received March 15, 2016; Accepted March 20, 2017

DOI: $10.3892 / \mathrm{mmr} .2017 .6834$

\begin{abstract}
Hepatic glycoprotein (gp78), a membrane-anchored E3 ubiquitin ligase, has been reported to be involved in regulating lipid and energy metabolism in animals, and cell death-inducing DFFA-like effector c (cidec) has emerged as an important regulator of metabolism, which has been implicated in the process of fat differentiation. Nonalcoholic fatty liver disease is a metabolic disorder associated with hepatic steatosis. In the present study, to investigate the role of gp78 and cidec in hepatic steatosis, an in vitro cell culture model of hepatic steatosis was established, using the AML12 mouse hepatocyte cell line to assess the protein expression of gp78. The results of Oil Red O staining, phase contrast microscopy and triglyceride content detection experiments indicated that the overexpression of gp78 induced lipid accumulation, whereas gp78-knockdown led to a reduction in lipid accumulation in the AML12 cells. The increased expression of gp78 was associated with steatosis. The expression of cidec was consistent with gp78, and the colocalization of gp78 and cidec was observed on the surface of lipid droplets using immunofluorescence analysis. Furthermore, an interaction between gp78 and cidec was detected using coimmunoprecipitation analysis, and this interaction promoted lipid accumulation. Based on these data, it was hypothesized that gp78 is a regulator of hepatic steatosis, and that it may be a putative molecular mediator in metabolic diseases.
\end{abstract}

\section{Introduction}

Nonalcoholic fatty liver disease (NAFLD) is the most common global cause of chronic liver disease and is caused by

Correspondence to: Professor Qing Li or Dr Yuqiao Xu, State Key Laboratory of Cancer Biology, Department of Pathology, Xijing Hospital, Basic Medical College, Fourth Military Medical University, 169 Changle West Road, Xi'an, Shaanxi 710032, P.R. China

E-mail: liqing@fmmu.edu.cn

E-mail: yuqiaoxu@fmmu.edu.cn

\section{${ }^{*}$ Contributed equally}

Key words: glycoprotein 78, hepatic cell, steatosis, lipids, cell death-inducing DFFA-like effector c fat deposition (steatosis) in hepatocytes, which includes simple steatosis and nonalcoholic steatohepatitis (NASH). Steatosis is defined as the presence of hepatic triglyceride (TG) droplets in $>5 \%$ of hepatocytes (1). The accumulation of free cholesterol in NAFLD and NASH has also been reported (2). The incidence of NAFLD is rapidly increasing. It has a complex pathophysiology, is closely associated with metabolic syndrome, and is associated with metabolic risk factors, including obesity, type 2 diabetes mellitus and dyslipidemia $(3,4)$. NASH is considered to be a hepatic manifestation of metabolic syndrome (5), which can lead to hepatic injury, fibrosis, cirrhosis and hepatocellular carcinoma (1). It is also associated with metabolic impairment and the dysregulation of endoplasmic reticulum (ER) homeostasis.

Glycoprotein 78 (gp78), also identified as autocrine motility factor receptor (AMFR), is an ER membrane-anchored E3 ligase (6), which may be critical in protecting cultured cells against the disruption of ER homeostasis (7). Several studies have shown that genetic disruption of gp78 in aged mice induces hepatic steatosis fatty liver, inflammation and spontaneous hepatocellular cancer (8-10). However, conflicting results have been reported following the observation that liver-specific gp78-knockout mice were lean, and had lower blood and tissue lipid levels, with evidence to suggest that gp78 ubiquitinates HMG-CoA reductase, an enzyme involved in regulating the rate of cholesterol production, and is a metabolic regulator of genes involved in lipid metabolism (11). Further investigations involving different mouse strains and in vitro cell cultures may assist in improving current understanding of the role of gp78 in hepatic steatosis.

Cell death-inducing DFFA-like effector c (cidec), a human homologue of the murine fat-specific protein 27 (FSP27) is an adipocyte lipid droplet protein, which is important in lipid droplet formation $(12,13)$. It is only expressed in mature adipocytes and is associated with adipocyte differentiation $(14,15)$, and loss of cidec can impede adipocyte maturation (16). High expression levels have been identified in fatty liver syndrome, but not in the normal healthy liver $(17,18)$. In addition, obesity caused by a high fat diet can be prevented in FSP27-knockout mice, with these animals exhibiting a lean phenotype $(19,20)$. However, the exact mechanism underlying the effect of cidec in the regulation of adipocyte differentiation remains to be fully elucidated.

In the present study, the role of gp78 and cidec in hepatic steatosis were examined by application of an in vitro hepatocyte cell culture model. 


\section{Materials and methods}

Plasmid construction. Total RNA was extracted from the AM12 cells using RNAiso Plus (Takara Biotechnology Co., Ltd., Dalian, China) and cDNA was synthesized using an RT reagent kit (RR047Q; Takara Biotechnology Co., Ltd.). Using cDNA as the template, the gp78 length of the target fragment was amplified by reverse transcription-quantitative polymerase chain reaction (RT-PCR). The eukaryotic expression plasmid, pCMV5-HA (Biovector, Beijing, China), was digested with $N d e \mathrm{I}$ and $\mathrm{XbaI}$, and the gp78 fragment was inserted into the pCMV5-HA plasmid by overnight incubation with T4 DNA ligase at $16^{\circ} \mathrm{C}$. The pCMV5-HA-gp78 construct was extracted using $10 \mathrm{mg} / \mathrm{ml}$ agarose gel electrophoresis and transformed into the host bacteria DH5 $\alpha$ (18265017; Invitrogen, Beijing, China). The plasmid constructs were extracted using a Plasmid Midi kit according to the manufacturer's protocol (12843; Qiagen, Inc., Valencia, CA, USA) and enzyme digestion, and sent to Beijing Aoke Biological Technology Co. Ltd. (Beijing, China), where the plasmid construct was sequenced.

Design and verification of the small interfering (si) RNA gp 78 interference sequence and control sequence. The following sequences were used for verification of the gp78 interference sequence: siRNA gp78, sense 5'-GCAUGCACACCUUGG CUUUTT-3' and antisense 5'-AAAGCCAAGGUGUGC AUGCTT-3'; scramble RNA of gp78 (negative control), sense 5'-UUCUCCGAACGUGUCACGUTT-3' and antisense 5'-ACGUGACACGUUCGGAGAATT-3'. The interference RNA and negative control RNA were transfected into the AML12 mouse hepatocyte cells, and the cells were collected following incubation at $37^{\circ} \mathrm{C}$ for $48 \mathrm{~h}$. The total RNA was extracted, and the mRNA expression of gp78 was assessed using reverse transcription-quantitative polymerase chain reaction (RT-qPCR) analysis. The effect of siRNA on gp78 was also assessed.

Cell culture and transfection. The AML12 cells (CRL-2254; American Type Culture Collection, Manassas, VA, USA) were maintained in DMEM:F-12 medium in 1:1 ratio (DF12) and supplemented with $10 \%$ fetal bovine serum (Sigma-Aldrich; Merck Millipore, Darmstadt, Germany), $0.005 \mathrm{mg} / \mathrm{ml}$ insulin (Kehao Biological Engineering Co. Ltd., Xi'an, China), $0.005 \mathrm{mg} / \mathrm{ml}$ transferrin (Kehao Biological Engineering Co. Ltd.), $0.04 \mathrm{mg} / \mathrm{ml}$ hexadecadrol (Kehao Biological Engineering Co. Ltd.), and incubated at $37^{\circ} \mathrm{C}$ in an atmosphere of $5 \% \mathrm{CO}_{2}$. The cells were transfected with plasmids using Lipofectamine ${ }^{\circledR} 2000$ transfection reagent (Invitrogen; Thermo Fisher Scientific, Inc., Waltham, MA, USA), according to the manufacturer's protocol.

Oil Red O staining. The AM12 cells were stimulated with $400 \mu \mathrm{M}$ oleic acid, as previously described (21). Lipid accumulation in the AML12 cells was assessed using Oil Red O staining. In brief, the cells were fixed onto slides at a concentration of $2 \times 10^{6} \mathrm{cells} / \mathrm{ml}$ with $4 \%$ polyformaldehyde for at least $30 \mathrm{~min}$, washed with phosphate-buffered saline (PBS) and immersed in freshly prepared 2\% Oil Red O (Sigma-Aldrich; Merck Millipore) dye at room temperature for $25 \mathrm{~min}$. The slides were then washed in 60\% isopropanol (Invitrogen;
Thermo Fisher Scientific, Inc.) followed by distilled water. A phase contrast microscope was used to visualize staining.

Western blot analysis. The AML12 cells were seeded at a concentration of $3 \times 10^{6}$ cells $/ \mathrm{ml}$ into $60 \mathrm{~mm}$ dishes and, once confluent, were lysed in ice-cold lysis buffer containing $1 \%$ NP-40, $50 \mathrm{mM}$ Tris-HCl, $0.1 \%$ SDS, $1 \%$ sodium deoxycholate and $150 \mathrm{mM} \mathrm{NaCl}(\mathrm{pH}$ 7.4; Tianjin Chemical Reagent Factory, Tianjin, China) and centrifuged at $12,000 \mathrm{xg}$ at $4^{\circ} \mathrm{C}$ for $3 \mathrm{~min}$. The protein content was determined using Quick Start ${ }^{\mathrm{TM}}$ Bradford kit (5000202EDU; Bio-Rad Laboratories, Inc., Hercules, CA, USA), using bovine serum albumin (BSA) as the standard. Subsequently, $15 \mu \mathrm{l}$ of the proteins were separated by SDS-PAGE on $12 \%$ acrylamide gels, following which proteins were transferred onto a PVDF membrane (EMD Millipore, Bethesda, MA, USA). The membrane was then incubated overnight in a blocking buffer containing appropriate diluent (ab64211; Abcam, Cambridge, UK) of primary antibodies against gp78 (ab54787; 1:1,000, Abcam), cidec (ab77115; 1:1,000, Abcam), PPAR- $\gamma$ (ab41928; 1:1,000, Abcam) and $\beta$-actin (ab8226; 1:1,000, Abcam) at $4^{\circ} \mathrm{C}$. The proteins were detected by incubation with horseradish peroxidase-conjugated secondary antibody (ab6789; 1:2,000, Abcam) in diluent (ab64211; Abcam, Cambridge, UK) at room temperature for $1 \mathrm{~h}$. Following extensive washing with Tris-buffered saline (pH 7.2) containing $0.05 \%$ Tween 20 , the bands were visualized using enhanced chemiluminescence and autoradiography.

Lipid extraction and triglyceride $(T G)$ content determination. To measure the total TG levels, lipids were extracted from the cells using the Folch method, as previously described (22). Briefly, the cells at a concentration of $3 \times 10^{6}$ cells $/ \mathrm{ml}$ were washed with PBS, scraped in $1 \mathrm{ml}$ PBS and transferred into a 15-ml tube. Intermixture was added ( $8 \mathrm{ml}$ of n-hexane: dimethyl carbinol in a $3: 2$ ratio) and centrifuged $\left(4^{\circ} \mathrm{C}, 12,000 \mathrm{xg}, 5 \mathrm{~min}\right)$. The supernatant was removed into a glass tube, and $0.1 \mathrm{ml}$ $2 \%$ Tritonx-100 was added using a dry nitrogen-blowing instrument, followed by shock mixing storage at $-20^{\circ} \mathrm{C}$. TG content was quantified using Bio-Rad QuantityOne software version 4.62 (Bio-Rad Laboratories, Inc.).

RNA isolation and RT-qPCR analysis. Total RNA was extracted from the AML12 cells using TRIzol (Invitrogen; Thermo Fisher Scientific, Inc.) Total RNA was converted into complementary DNA using avian myeloblastosis virus reverse transcriptase (Takara Bio, Inc., Otsu, Japan). The primers (forward, 5'-CCTGGCTAGAACAAGACACC-3' and reverse, 5'-ATCCGAGACCCATCGAAA. T-3') were synthesized by Aoke Company (Beijing, China). RT-qPCR was used to quantify the complementary DNA template. Quantitative gene expression analysis was performed using the SYBR ${ }^{\circledR}$ Premix Ex Taq ${ }^{\mathrm{TM}}$ GC (RR071Q; Takara Bio, Inc.) and normalized relative to the $\beta$-actin mRNA control band. The reaction system included $12.5 \mu \mathrm{l}$ of SYBR Premix Ex Taq GC, $0.5 \mu l$ of forward primer, $0.5 \mu \mathrm{l}$ of reverse primer, $2 \mu \mathrm{l}$ of template and $9.5 \mu \mathrm{l}$ of $\mathrm{H}_{2} \mathrm{O}$. The reactions were incubated in 96-well optical plates for initial denaturation at $95^{\circ} \mathrm{C}$ for 3 min followed by 35 cycles of denaturation at at $95^{\circ} \mathrm{C}$ for $15 \mathrm{sec}$, annealing at $60^{\circ} \mathrm{C}$ for $30 \mathrm{sec}$, extension at $72^{\circ} \mathrm{C}$ for $30 \mathrm{sec}$ then followed by a final extension at $72^{\circ} \mathrm{C}$ for $10 \mathrm{~min}$. 
A
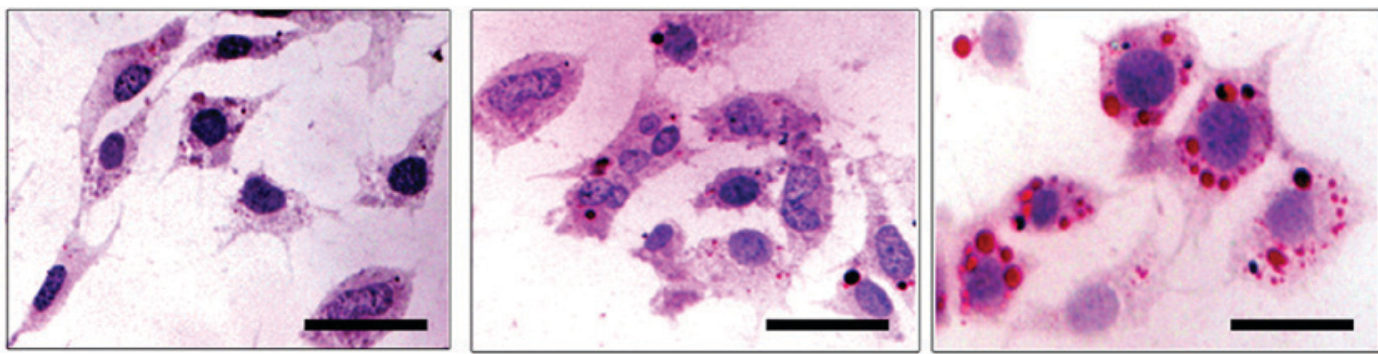

B

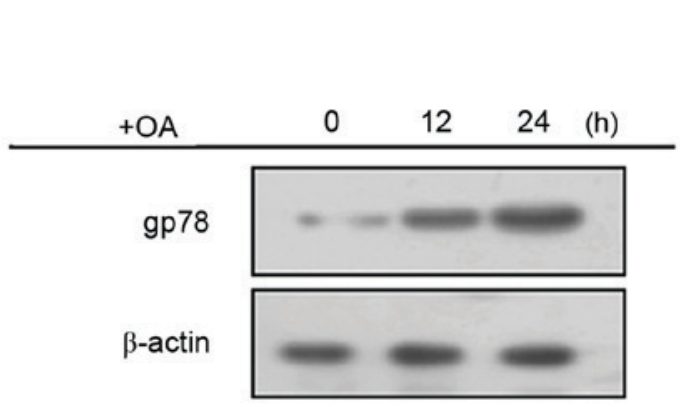

C

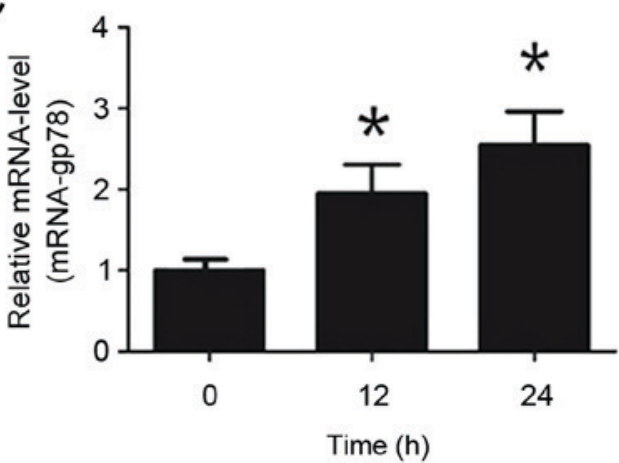

Figure 1. Elevated expression levels of gp78 in the process of hepatic steatosis. (A) Stimulating cells with OA at 0, 12 and $24 \mathrm{~h}$ increased lipid accumulation in AML12 cells (scale bar=20 $\mu \mathrm{m}$ ), as observed by Oil Red O staining. (B) Increased protein expression of gp78 above basal levels was observed in hepatic steatosis, as determined using western blot analysis. (C) Reverse transcription-quantitative polymerase chain reaction assessment of mRNA expression levels of gp78, which were upregulated in hepatic steatosis. The relative mRNA level in the control group was designated as 1.0 . ( $\mathrm{P}<0.05$, vs. control; $\mathrm{n}=3$ ). OA, oleic acid; gp78, glycoprotein 78 .

Immunofluorescence assay. The AML12 cells were seeded onto sterile coverslips and, following incubation at $37^{\circ} \mathrm{C}$ for $24 \mathrm{~h}$, the cells were transfected with pCMV-Myc-CIDE-3 and pCMV5-HA-gp78 for $48 \mathrm{~h}$, and in 5\% BSA for $30 \mathrm{~min}$. The cells were then incubated with primary antibodies specific for gp78 (ab54787; dilutions 1:1,000, Abcam) or cidec (ab213693; dilutions 1:1,000, Abcam) overnight at $4^{\circ} \mathrm{C}$, followed by incubation with secondary antibodies conjugated with fluorescein isothiocyanate for gp78 (ab6785; dilutions 1:3,000, Abcam) and with tetraethyl rhodamine isothiocyanate for cidec (ab6718; 1:3,000, Abcam) for $1 \mathrm{~h}$ at $37^{\circ} \mathrm{C}$. Prior to imaging, the cells were counterstained with DAPI (Invitrogen; Thermo Fisher Scientific, Inc.) for $10 \mathrm{~min}$ at $37^{\circ} \mathrm{C}$ to stain the nuclei, and were visualized with an E1000 digital camera (Nikon Corporation, Tokyo, Japan) with SimplePCI software version 65 (Meyer Instruments, Houston, TX, USA).

Coimmunoprecipitation assay. The cells were cultured in $60-\mathrm{mm}$ dishes at a concentration of $3 \times 10^{6}$ cells $/ \mathrm{ml}$ and were cotransfected with $5 \mu \mathrm{g}$ of pCMV-Myc-CIDE-3 and pCMV5-HA-gp78. The cells were lysed with RIPA buffer containing $150 \mathrm{mM} \mathrm{NaCl}, 1 \% \mathrm{NP} 40,0.5 \%$ sodium deoxycholate, $0.1 \%$ SDS and $50 \mathrm{mM}$ Tris- $\mathrm{HCl}$ (pH 7.5; Tianjin Chemical Reagent Factory). The cells were incubated for $10 \mathrm{~min}$ on ice and, following brief sonication, the lysate was centrifuged at $12,000 \mathrm{x} \mathrm{g}$ for $10 \mathrm{~min}$ at $4^{\circ} \mathrm{C}$. An aliquot of the lysates was removed for western blot analysis. Antibody was coupled to Dynabeads ${ }^{\circledR}$ Protein G (Dynal; thermo Fisher Scientific, Inc.) using dimethylpimelimidate coupling according to the manufacturer's protocol. Equal quantities of cellular protein were incubated for $2 \mathrm{~h}$ with the antibody-linked beads at $4^{\circ} \mathrm{C}$ with continuous agitation. The lysates and coimmunoprecipitates were then separated by SDS-PAGE using 12\% gels and transferred onto PVDF membranes for western blot analysis.

Statistical analysis. All data are analyzed using SPSS 12.0 software (SPSS Inc., Chicago, IL, USA). Data are expressed as the means \pm standard error of the mean. Two-tailed Student's $\mathrm{t}$ test was used to compare the values between two groups. One-way analysis of variance was used to compare values between multiple groups. $\mathrm{P} \leq 0.05$ was considered to indicate a statistically significant difference.

\section{Results}

Elevated expression levels of gp78 in the process of hepatic steatosis. In the present study, steatosis was induced by oleic acid in AML12, and the cells were collected at 0,12 and $24 \mathrm{~h}$ for Oil Red O staining (Fig. 1A) and phase contrast microscopy (Fig. 1B). Increased lipid accumulation in liver cells was observed with time. The protein and mRNA expression levels of gp78 were confirmed using western blot and RT-qPCR analyses, respectively (Fig. 1C and D). Compared with the control group, the hepatocytes in the steatosis group showed increased expression of gp78 with time.

Effects of the overexpression and knockdown of $g p 78$ in hepatic steatosis. At $48 \mathrm{~h}$ post-transfection, the following three 
A

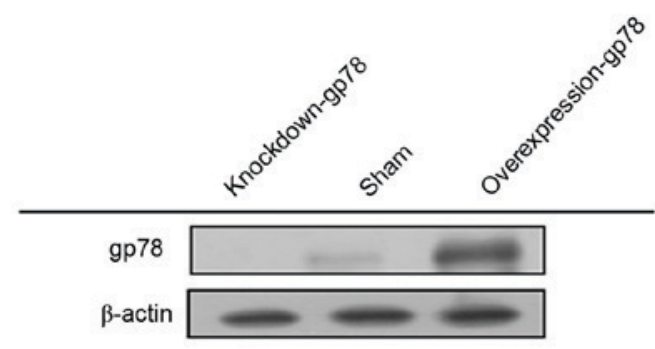

B

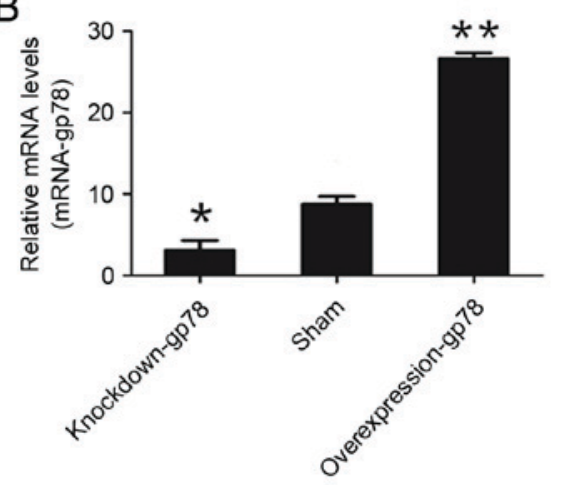

C

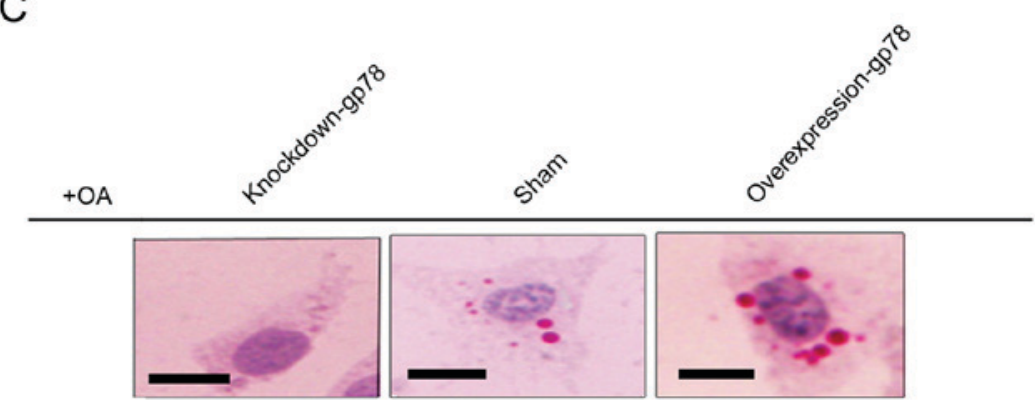

D

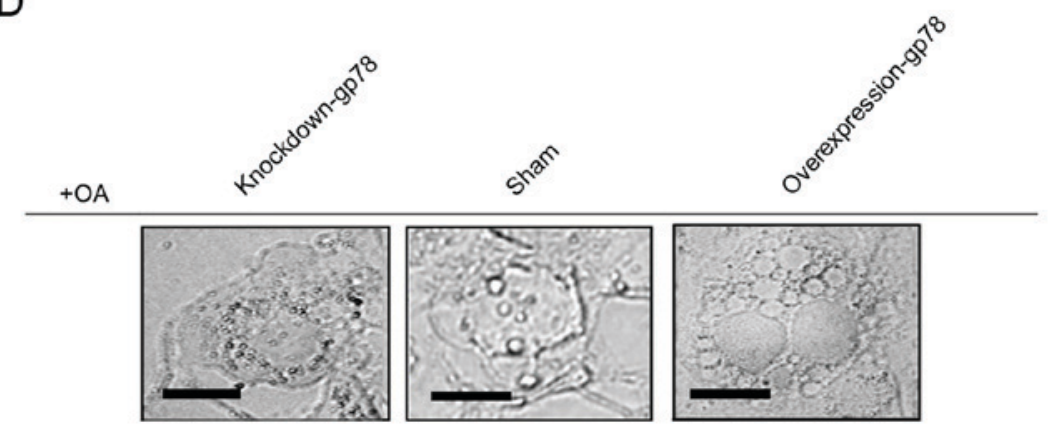

Figure 2. Role of gp78 in hepatic steatosis. (A) Western blot analysis of AML12 cells transfected with the gp78 plasmid (overexpression of gp78) or gp78-siRNA (gp78-knockdown). (B) Reverse transcription-quantitative polymerase chain reaction analysis of AML12 cells transfected with gp78 plasmid or gp78-siRNA. The relative mRNA level in the control group was designated as 1.0. $\left({ }^{*} \mathrm{P}<0.05{ }^{* *} \mathrm{P}<0.01\right.$, vs. control; $\left.\mathrm{n}=3\right)$. (C) Oil Red O staining analysis of AML12 cells transfected with the gp78 plasmid or gp78-siRNA to assess lipid accumulation (scale bar=20 $\mu \mathrm{m}$ ). (D) Phase contrast microscopic analysis of AML12 cells transfected with the gp78 plasmid or gp78-siRNA (scale bar=20 $\mu \mathrm{m}$ ). Compared with the control group, an increased number and volume of lipid droplets were observed in AML12 cells overexpressing gp78, whereas a decreased number and volume of lipid droplets were observed in the gp78-knockdown group. OA, oleic acid; gp78, glycoprotein 78 .

groups of cells were collected: Control group; gp78-overexpression group; and gp78-knockdown group. Western blot and RT-qPCR analyses were used to confirm the protein and mRNA expression of gp78, respectively (Fig. 2A and B). The lipid accumulation in heptocytes was observed using Oil Red O staining (Fig. 2C) and phase contrast microscopy (Fig. 2D). Compared with the control group, an increased number and volume of lipid droplets were observed in the gp78-overexpression group, whereas a decreased number and volume of lipid droplets were observed in the gp78-knockdown group.

Roles of gp78 and cidec in hepatic steatosis. The expression levels of cidec and peroxisome proliferator-activated receptor (PPAR)- $\gamma$ were upregulated, which was observed consistently with the overexpression of gp78 (Fig. 3A). The results suggested that the interaction between gp78 and cidec promoted lipid accumulation (Fig. 3B and C).

Association between gp78 and cidec in hepatic steatosis. The present study found that the interaction between gp78 and cidec promoted lipid accumulation using coimmunoprecipitation and immunofluorescence confocal microscopy analyses (Fig. 4A and B), which indicated that gp78 and cidec had the same localization in the AML12 cells.

\section{Discussion}

Although NAFLD is a commonly occurring liver disorder in industrialized countries (23), the majority of patients present with few or no symptoms. NAFLD is considered to be the 


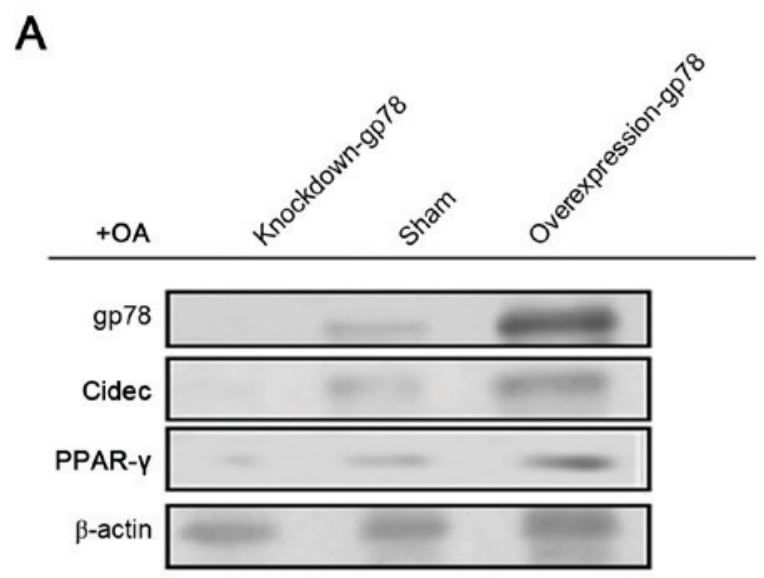

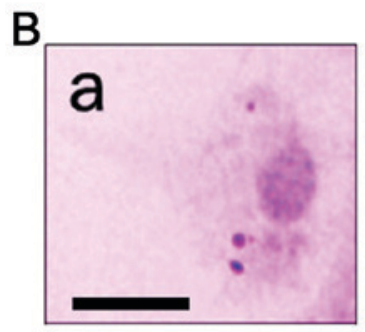
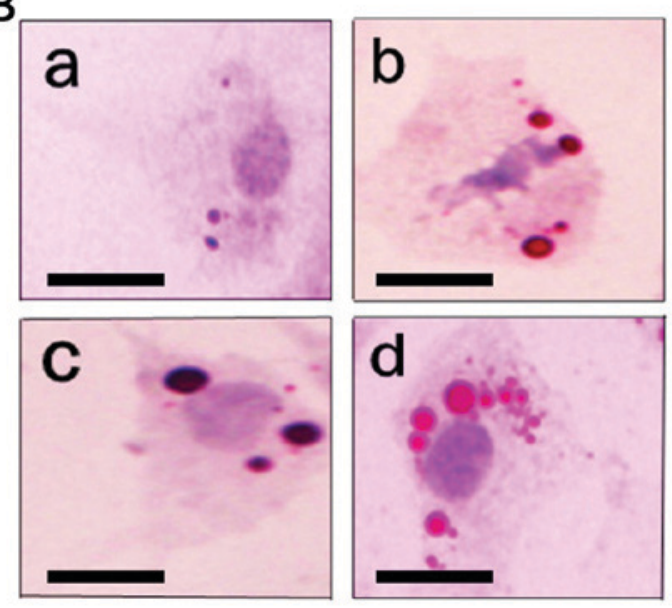

C

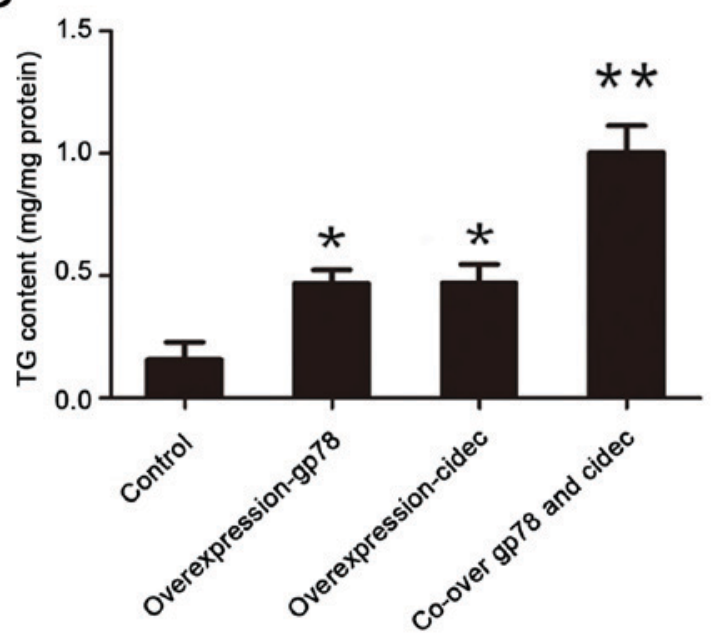

Figure 3. Role of gp78 and cidec in hepatic steatosis. (A) Western blot comparison of alterations in the expression of gp78, cidec and PPAR- $\gamma$. (B) Oil Red $\mathrm{O}$ analysis of the effect of gp78 and cidec on lipid accumulation (scale bar=20 $\mu \mathrm{m}$ ). (a) Control, (b) overexpression gp78, (c) overexpression cidec and (d) co-overexpression of gp78 and cidec groups. (C) Quantification of TG concentrations to assess the combined effect of gp78 and cidec on lipid accumulation. All data are expressed as the mean \pm standard error of the mean for each group. ( $\mathrm{P}<0.05$ and ${ }^{* *} \mathrm{P}<0.01$, vs. control; $\mathrm{n}=4$ ). gp 78 , glycoprotein; cidec, cell death-inducing DFFA-like effector c; TG, hepatic triglyceride; PPAR- $\gamma$, peroxisome proliferator-activated receptor- $\gamma$.
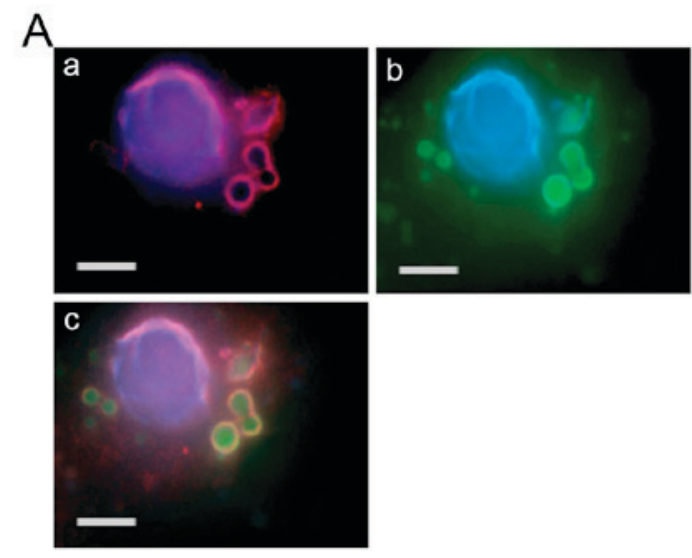

Figure 4. Association between gp78 and cidec in hepatic steatosis. (A) Nuclei were stained with DAPI, (a) gp78 was visualized (fluorescein isothiocyanate conjugated secondary antibody; red staining). (b) Cidec was visualized (tetraethyl rhodamine isothiocyanate conjugated secondary antibody; green staining); (c) Colocalization of gp78 and cidec (yellow) visualized on the surface of lipid droplets using immunofluorescent microscopy and identified by coimmunoprecipitation (scale bar=15 $\mu \mathrm{m}$ ). (B) Gp78 and Cidec direct interaction detected by coimmunoprecipitation assay. gp78, glycoprotein; cidec, cell death-inducing DFFA-like effector c.

most common cause of chronic liver disease, cirrhosis and liver failure $(24,25)$. Furthermore, dysregulated cholesterol
B

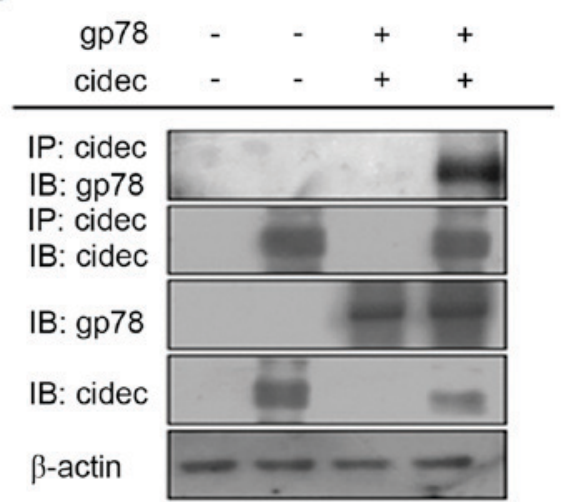


through a cascade of enzymatic reactions (27), and hepatic gp78 has been reported to be essential in regulating lipid and energy metabolism in animals. However, the exact mechanism by which this regulation takes place remains controversial $(10,11,28,29)$.

In the present study, the expression of gp78 was examined in hepatic steatosis and it was observed that the hepatocytes in the steatosis group showed increased expression of gp78 expression over time. Furthermore, the overexpression of gp78 induced lipid accumulation in hepatocytes, whereas the knockdown of gp78 led to a reduction in lipid accumulation, which indicates its potential role in the biosynthesis of cholesterol and fatty acids in the liver (11). However, further investigations are required to determine the exact mechanism underlying the role of gp78 in hepatic steatosis.

The cell death-inducing DNA fragmentation factor 45-like effector proteins are important in lipid metabolism (30). Cidec is expressed at high levels in white adipose tissue and increases during adipogenesis in mice $(12,15)$. In addition, it has been demonstrated that cidec induces apoptosis in hepatocellular carcinoma (31). PPAR- $\gamma$ is primarily present in adipose tissue, and it regulates fatty acid storage and glucose metabolism (32). The genes activated by PPAR- $\gamma$ stimulate lipid uptake and adipogenesis by fat cells, and PPAR- $\gamma$-knockout mice fail to generate adipose tissue when fed a high fat diet (32). In the present study, it was found that the overexpression of gp78 upregulates the expression of cidec and PPAR- $\gamma$, whereas knocking down gp78 had a suppressive effect. The interaction between gp78 and cidec induced lipid accumulation in hepatocytes.

In conclusion, the present study is the first, to the best of our knowledge, to demonstratef an association between gp78 and cidec, and show their combined effect on hepatic steatosis. However, the involvement of gp78 and cidec in NAFLD requires further experimental investigation.

\section{Acknowledgements}

This study was supported by Grants from National Natural Science Foundation of China (grant nos. 81170798, 81000171 and 31400722.).

\section{References}

1. Cohen JC, Horton JD and Hobbs HH: Human fatty liver disease: Old questions and new insights. Science 332: 1519-1523, 2011.

2. Puri P, Baillie RA, Wiest MM, Mirshahi F, Choudhury J, Cheung O, Sargeant C, Contos MJ and Sanyal AJ: A lipidomic analysis of nonalcoholic fatty liver disease. Hepatology 46: 1081-1090, 2007

3. Nascimbeni F, Pais R, Bellentani S, Day CP, Ratziu V, Loria P and Lonardo A: From NAFLD in clinical practice to answers from guidelines. J Hepatol 59: 859-871, 2013.

4. Chalasani N, Younossi Z, Lavine JE, Diehl AM, Brunt EM, Cusi K, Charlton M and Sanyal AJ: The diagnosis and management of non-alcoholic fatty liver disease: Practice guideline by the American association for the study of liver diseases, American college of gastroenterology and the American gastroenterological association. Hepatology 55: 2005-2023, 2012.

5. Marchesini G, Bugianesi E, Forlani G, Cerrelli F, Lenzi M, Manini R, Natale S, Vanni E, Villanova N, Melchionda N and Rizzetto M: Nonalcoholic fatty liver, steatohepatitis, and the metabolic syndrome. Hepatology 37: 917-923, 2003.

6. Fairbank M, St-Pierre P and Nabi IR: The complex biology of autocrine motility factor/phosphoglucose isomerase (AMF/PGI) and its receptor, the gp78/AMFR E3 ubiquitin ligase. Mol Biosyst 5: 793-801, 2009.
7. Song BL, Javitt NB and DeBose-Boyd RA: Insig-mediated degradation of HMG CoA reductase stimulated by lanosterol, an intermediate in the synthesis of cholesterol. Cell Metab 1: 179-189, 2005.

8. Song BL, Sever N and DeBose-Boyd RA: Gp78, a membrane-anchored ubiquitin ligase, associates with Insig-1 and couples sterol-regulated ubiquitination to degradation of $\mathrm{HMG}$ CoA reductase. Mol Cell 19: 829-840, 2005.

9. Shen Y, Ballar P, Apostolou A, Doong H and Fang S: ER stress differentially regulates the stabilities of ERAD ubiquitin ligases and their substrates. Biochem Biophys Res Commun 352: 919-924, 2007.

10. Zhang T, Kho DH, Wang Y, Harazono Y, Nakajima K, Xie Y and Raz A: Gp78, an E3 ubiquitin ligase acts as a gatekeeper suppressing nonalcoholic steatohepatitis (NASH) and liver cancer. PLoS One 10: e0118448, 2015.

11. Liu TF, Tang JJ, Li PS, Shen Y, Li JG, Miao HH, Li BL and Song BL: Ablation of gp78 in liver improves hyperlipidemia and insulin resistance by inhibiting SREBP to decrease lipid biosynthesis. Cell Metab 16: 213-225, 2012.

12. Puri V, Konda S, Ranjit S, Aouadi M, Chawla A, Chouinard M, Chakladar A and Czech MP: Fat-specific protein 27, a novel lipid droplet protein that enhances triglyceride storage. J Biol Chem 282: 34213-34218, 2007.

13. Min J, Zhang W, Gu Y, Hong L, Yao L, Li F, Zhao D, Feng Y, Zhang $\mathrm{H}$ and $\mathrm{Li} \mathrm{Q}$ : CIDE-3 interacts with lipopolysaccharide-induced tumor necrosis factor, and overexpression increases apoptosis in hepatocellular carcinoma. Med Oncol 28 (Suppl 1): S219-S227, 2011

14. Danesch U, Hoeck W and Ringold GM: Cloning and transcriptional regulation of a novel adipocyte-specific gene, FSP27. CAAT-enhancer-binding protein $(\mathrm{C} / \mathrm{EBP})$ and $\mathrm{C} / \mathrm{EBP}-$ like proteins interact with sequences required for differentiation-dependent expression. J Biol Chem 267: 7185-7193, 1992.

15. Kim JY, Liu K, Zhou S, Tillison K, Wu Y and Smas CM: Assessment of fat-specific protein 27 in the adipocyte lineage suggests a dual role for FSP27 in adipocyte metabolism and cell death. Am J Physiol Endocrinol Metab 294: E654-E667, 2008.

16. Li F, Gu Y, Dong W, Li H, Zhang L, Li N, Li W, Zhang L, Song Y, Jiang L, et al: Cell death-inducing DFF45-like effector, a lipid droplet-associated protein, might be involved in the differentiation of human adipocytes. FEBS J 277: 4173-4183, 2010.

17. Toh SY, Gong J, Du G, Li JZ, Yang S, Ye J, Yao H, Zhang Y, Xue B, Li Q, et al: Up-regulation of mitochondrial activity and acquirement of brown adipose tissue-like property in the white adipose tissue of fsp27 deficient mice. PLoS One 3: e2890, 2008.

18. Guillen N, Navarro MA, Arnal C, Noone E, Arbonés-Mainar JM, Acín S, Surra JC, Muniesa P, Roche HM and Osada J: Microarray analysis of hepatic gene expression identifies new genes involved in steatotic liver. Physiol Genomics 37: 187-198, 2009.

19. Puri V and Czech MP: Lipid droplets: FSP27 knockout enhances their sizzle. J Clin Invest 118: 2693-2696, 2008.

20. Matsusue K, Kusakabe T, Noguchi T, Takiguchi S, Suzuki T, Yamano S and Gonzalez FJ: Hepatic steatosis in leptin-deficient mice is promoted by the PPARgamma target gene Fsp27. Cell Metab 7: 302-311, 2008.

21. Jiang L, Gu Y, Ye J, Liu F, Zhao Y, Wang C, Xu Y, Cao X, Zhang L, Dong W, et al: Resveratrol prevents hepatic steatosis induced by hepatitis $\mathrm{C}$ virus core protein. Biotechnol Lett 34 : 2205-2212, 2012.

22. Folch J, Lees M and Sloane Stanley GH: A simple method for the isolation and purification of total lipides from animal tissues. J Biol Chem 226: 497-509, 1957.

23. Shaker M, Tabbaa A, Albeldawi M and Alkhouri N: Liver transplantation for nonalcoholic fatty liver disease: New challenges and new opportunities. World J Gastroenterol 20: 5320-5330, 2014.

24. Moore JB: Non-alcoholic fatty liver disease: The hepatic consequence of obesity and the metabolic syndrome. Proc Nutr Soc 69: 211-220, 2010.

25. White DL, Kanwal F and El-Serag HB: Association between nonalcoholic fatty liver disease and risk for hepatocellular cancer, based on systematic review. Clin Gastroenterol Hepatol 10: 1342-1359.e2, 2012.

26. Min HK, Kapoor A, Fuchs M, Mirshahi F, Zhou H, Maher J, Kellum J, Warnick R, Contos MJ and Sanyal AJ: Increased hepatic synthesis and dysregulation of cholesterol metabolism is associated with the severity of nonalcoholic fatty liver disease. Cell Metab 15: 665-674, 2012. 
27. Goldstein JL, DeBose-Boyd RA and Brown MS: Protein sensors for membrane sterols. Cell 124: 35-46, 2006.

28. Travers KJ, Patil CK, Wodicka L, Lockhart DJ, Weissman JS and Walter P: Functional and genomic analyses reveal an essential coordination between the unfolded protein response and ER-associated degradation. Cell 101: 249-258, 2000.

29. Chen Z, Ballar P, Fu Y, Luo J, Du S and Fang S: The E3 ubiquitin ligase gp78 protects against ER stress in zebrafish liver. J Genet Genomics 41: 357-368, 2014.

30. Gong J, Sun Z and Li P: CIDE proteins and metabolic disorders. Curr Opin Lipidol 20: 121-126, 2009.
31. Greene ME, Blumberg B, McBride OW, Yi HF, Kronquist K, Kwan K, Hsieh L, Greene G and Nimer SD: Isolation of the human peroxisome proliferator activated receptor gamma cDNA: Expression in hematopoietic cells and chromosomal mapping. Gene Expr 4: 281-299, 1995.

32. Jones JR, Barrick C, Kim KA, Lindner J, Blondeau B, Fujimoto Y, Shiota M, Kesterson RA, Kahn BB and Magnuson MA: Deletion of PPARgamma in adipose tissues of mice protects against high fat diet-induced obesity and insulin resistance. Proc Natl Acad Sci USA 102: 6207-6212, 2005. 